\title{
Biosafety Issues in Commercialization and Development of Transgenic Crops
}

\author{
Manoj Kumar ${ }^{1 *}$, S.P. Singh ${ }^{2}$, Mankesh Kumar², Anand Kumar ${ }^{2}$, \\ Satyendra Kumar ${ }^{2}$ and Priti Kumari ${ }^{2}$ \\ ${ }^{1}$ RRSS, Jalalgarh, BAU, Sabour, Bhagalpur, India \\ ${ }^{2}$ Department of $P B G, B A U$, Sabour, India \\ *Corresponding author
}

Ke y w o r d s
Biosafety,
Commercialization,
Transgenic
technology

\section{Introduction}

Application of transgenic technology for commercial crop production is facing biosafety issues. Unlike conventional breeding, recombinant DNA-based transgenic
A B S T R A C T

Application of transgenic technology for commercial crop production is faced with biosafety issues. These concerns are based on the argument that recombinant DNA-based transgenic technology differs from traditional breeding in that totally new gens using potentially risky technology are transferred between widely unrelated organisms and the location of these genes on the recipient genome is random, unlike when gene transfer take place through conventional breeding. These differences demands that adequate laboratory safeguards are used and plant developed by GM technology are rigorously assessed for their performance as also for the likely risks they pose. At present transgenics crops are under the purview of the Union Ministry of Environment, Forests and climate Change (MoEF \& CC) under the Environment Protection Act (EPA) 1986 and rule 1989. The rapid adoption of transgenics crops, during 1996 to 2015, reflects the substantial multiple benefits realized by both large and small farmers (18 millions) in 29 countries with an area $179.7 \mathrm{mha}$. USA is the largest producer of GM crops in the world with about $73.1 \mathrm{mha}$ of land under cultivation. Bt cotton, the only GM crop under cultivation in India, cover around (11.6 mha) $95 \%$ of the total cotton growing area and rank $4^{\text {th }}$ in world. A total of 1128 varieties of $\mathrm{Bt}$ cotton hybrid have been allowed to be commercially released by GEAC from 2002 to 2015. Transgenic technology offers potential to developed crop varieties with new genetic properties. The need for adopting adequate safety measures for development, environmental release and use of transgenic crops and their products is well appreciated. Biosafety protocols need to be followed at work place during development of GM crops and commercialization at farmer's fields. Basic research should continue on precise application in development of GM crops and simplification of biosafety protocols. 
rigorous assessment of performance of the plants developed by GM technology due to the likely risks they pose. At present, transgenics crops are under the purview of the Union Ministry of Environment, Forests and climate Change (MoEF \& CC) under the Environment Protection Act (EPA) 1986 and rule 1989. The rapid adoption of transgenic crops, during 1996 to 2015 (Fig. 1), reflects the substantial multiple benefits realized by both large and small farmers (18 millions) in 29 countries with an area 179.7 mha. USA is the largest producer of GM crops in the world with about 73.1 mha of land under cultivation. Bt cotton, the only GM crop under cultivation in India, cover around (11.6 mha) $95 \%$ of the total cotton growing area and rank $4^{\text {th }}$ in world. A total of 1128 varieties of Bt cotton hybrid have been allowed to be commercially released by GEAC from 2002 to 2015. Transgenic technology offers potential to developed crop varieties with new genetic properties. The need for adopting adequate safety measures for development, environmental release and use of transgenic crops and their products is well appreciated. Biosafety protocols needs to be followed at work place during development of GM crops and commercialization at farmer's fields. Basic research should be continued on development of GM crops and simplification of biosafety protocols.

Rapid adoption of GM crop from 1996 to 2015 reflects multiple benefits among 18 million farmers of 28 GM producing countries.

There are 9 developed countries and 19 developing countries producing GM crops. Among these five major countries, USA, Brazil, Argentina, India and Canada are contributing about $95 \%$ area of total global area under GM crops (Fig. 2).

India occupied $4^{\text {th }}$ rank in GM crops with an area $11.6 \mathrm{mha}$ and only cotton crops is commercially grown by the Indian farmers.
GM cotton crops are rapidly adopted by the farmers in Indian agricultural history (Fig. 3). The difference between the conventional breeding and transgenic breeding demands laboratory safeguard and rigorously assessment of the performance of transgenic plant and potential risk they pose.

In the past several years, several reports to examine the impact of GMOs on human health, environmental health, and economic health are coming out in literature. This topic has generated severe public debate in many parts of the world. Though, it is widely claimed that transgenic crops offers dramatic promise for meeting some of greatest challenges but like all new technologies, it also poses certain risks, because of the fact that transgenic crops can bring together new gene combinations which are not found in nature having possible harmful effects on health, environmental and non-target species. But results of different researches vary from country to country, depending on its geographic location, strength and resilience of the farm sector, attitudes of people towards food and so on. Some regions, such as the European Union, have established highly restrictive regulations in an effort to stop the spread of transgenic crops. The United States market is more open for transgenic crops and has most stringent food safety standard. USA promoting it at an impressive rate and expected to be the lead producer of transgenic crops globally because it has not experienced the same type of consumer criticism as has occurred in Europe (Fig. 4).

\section{Public perceptions towards transgenic food}

The Genetically modified technology is a dispute over the relative advantages and disadvantages of food derived from genetically modified organisms. The dispute involves consumers, biotechnology companies, governmental regulators, nongovernmental organizations and scientists. 
The key areas of controversy related to genetically modified (GM) food are: risk of harm from transgenic food, whether transgenic food should be labeled, the role of government regulators, the effect of transgenic crops on the environment, the impact of transgenic crops for farmers, the role of transgenic crops in feeding the growing world population and transgenic crops as part of the industrial agriculture system. There is broad scientific consensus that food on the market derived from GM crops poses no greater risk than conventional food. Supporters of GMOs hold that food is as safe as other foods. They trust that regulators and the regulatory process are sufficiently objective and rigorous. They trust that GM technology is a key to feeding a growing world population, and view GM technology as a continuation of the manipulation of plants that humans have conducted for millennia. Advocacy groups such as Greenpeace and World Wildlife Fund have concerns that risks of GM food have not been adequately identified and managed, and have questioned the objectivity of regulatory authorities. Opponents of GM food are concerned about the safety of the food itself and wish it banned or at least labeled. In 2006, the Pew Initiative on Food and Biotechnology made public a review of U.S. survey results from 2001-2006. During this period there were protests against Calgene's FlavrSavr transgenic tomato that described the GM tomato as being made with fish genes, confusing it with DNA Plant Technology's Fish tomato experimental transgenic organism, which was never commercialized. The Pew survey also showed that despite continuing concerns about GM foods, American consumers do not support banning new uses of the technology but rather seek a dynamic role from regulators to ensure that new products are safe. Approximately half of European consumers accepted gene technology particularly when benefits for consumers and for the environment could be linked to GMO products. $80 \%$ of respondents did not cite the application of GMOs in agriculture as a significant environmental problem. Many consumers seem unafraid of health risks from GMO products and most European consumers did not actively avoid GMO products while shopping. A 2007 survey by the Food Standards Australia and New Zealand found that in Australia where labeling is mandatory, $27 \%$ of Australians looked at the label to see if it contained GM material when purchasing a grocery product for the first time. There is a concerted and organized effort from many environmental and other advocacy groups to impose moratoriums or ban GMO products from being commercialized. International organizations like Greenpeace and Friends of the Earth include genetic engineering as part of their environmental and political concerns. Other groups like GM Watch and The Institute of Science in Society concentrate mostly or solely on opposing genetically modified crops. Too much of hue and cry has been made about safety aspect of transgenic crops in India. Despite impressive growth and substantial potential of transgenic crops, Indian policy towards it has not been encouraging. Brinjal has passed all the regulatory procedure that is formed by government of India and yet Government imposed a ban. It has put a question mark on future of GM foods in India. To observe the situation we have to determine that, are transgenic crops really dangerous for human health and food safety? Are they risky for our environment and the biological diversity? How can they help attain sustainability? What about the economics of transgenic crops? We also have to investigate that what scientific approach can be used to monitor and assess possible long-term health effects or unintended/unexpected adverse effects? What are the Principles of GM food safety assessment and regulatory system? Do we have safety mechanism in place and how authentic is our apprehension about safety? In 
short, we must consider several key points when assessing the safety of transgenic crops for production and commercialization.

\section{The impacts of transgenic crops on health and environment}

Health Governments worldwide access and manage the risks associated with transgenic crops. Regulators examine the genetic modification, its protein products, and any intended changes that those proteins make to the food. Regulators also check to see whether the food derived from a GMO is "substantially equivalent" to its non-GM derived counterpart. If the newly included protein is not similar to that of other proteins found in food or if difference arise in the substantial equivalence comparison, further toxicological testing is required. The American Association for the Advancement of Science stated "Foods containing ingredients from genetically modified (GM) crops pose no greater risk than the same foods made from crops modified by conventional plant breeding techniques". The European Commission Directorate-General for Research and Innovation 2010 report on GMOs noted that "The main conclusion to be drawn from the efforts of more than 130 research projects covering a period of more than 25 years of research and involving more than 500 independent research groups is that biotechnology, and in particular GMOs are not per se more risky than e.g. conventional plant breeding technologies". Approaches to Safety Evaluation need a high level safety standard for the new crops by setting up guidance for evaluation and development of pre-market approval systems that include extensive documentation, analysis and test. The argument for this high safety level which seems to be much higher than the safety level for traditional plants is the present limitation of experience (lack of history of safe intake) with transgenic crops. Concerted efforts have been made internationally to harmonize the risk assessment of transgenic crops as articulated in two important documents published in 2003 by the Codex Alimentarius Commission (CAC) "Principles for the Risk Analysis of Foods Derived from Modern Biotechnology" ("Codex Principles") and "Guideline for the Conduct of Food Safety Assessment of Foods Derived from Recombinant-DNA Plants". Several international organizations have already addressed the issues associated with the safety assessment of transgenic crops. The current approach of food safety assessment of transgenic crops is based on the concept of substantial equivalence. It is a key step in the safety assessment process. Although it does not characterize hazard, rather it is used to determine whether the genetically modified food is as safe as it's a conventional counterpart. The starting point for the safety assessment of transgenic food products by regulatory bodies is to assess if the food is "substantially equivalent" to their counterparts, which themselves are the products of genetic manipulation via traditional methods of cross-breeding and hybridization. Substantial equivalence is a concept, first described in an OECD (Organization for Economic Co-operation and Development) publication in 1993. It follows a stepwise process and factors taken into account in the safety assessment include identity, source, composition, effects of processing/cooking, transformation process, the recombinant DNA (e.g. stability of insertion, potential for gene transfer), protein expression product of the novel DNA, potential toxicity, potential allergenicity, possible secondary effects from gene expression or the disruption of the host DNA or metabolic pathways, including composition of critical macro, micro nutrients, antinutrients, endogenous toxicants and physiologically active substances and potential intake and dietary impact of the introduction of the genetically modified crops. The above 
factors are the assessment of foods derived from genetically modified plants. The safety assessment of GM foods has been based on the principle that these factors can be compared with traditional foods that have an established history of safe use. The concept of substantial equivalence was further endorsed by an FAO/WHO (Food and Agriculture Organization/World Health Organization) joint expert consultation in 1996. It recognized that the establishment of substantial equivalence is not a safety assessment per se, but that establishing the characteristics and composition of the GM food as equivalent to those of a familiar, conventional food with a history of safe consumption means that the new product will be no less safe under similar consumption patterns and processing practices. The concept of substantial equivalence also recognizes the fact that existing foods often contain toxic components (usually called anti nutrients) and are still able to be consumed safely for example the cassava root is quite toxic, but proper processing converts it into a nutritious and widely consumed food. Soybeans and Lima beans, among other crops, contain anti-nutrients (e.g., soybean trypsin inhibitor and lectins) and require proper processing. Potatoes and tomatoes can contain toxic levels of the Glycoalkaloids Solanine and $\alpha$-tomatine, respectively. Thus, the presence of a toxicant in a plant variety does not necessarily eliminate its use as a food source. In considering the safety of the GM food, it is therefore important to examine the range of possible toxicants, critical nutrients or other relevant factors, as well as its processing, intended use and exposure. The proposed indirect measurements using the substantial equivalence approach therefore do not result in $100 \%$ certainty on the absence of any toxicologically unwanted effects, but in a strong reduction of the likelihood that such unwanted effects have occurred. The fact that such effects can also occur in conventionally bred crops, makes that if no substantial differences are found, the modified crop is considered to be (at least) as safe as the conventionally bred varieties. The application of substantial equivalence has been criticized by Erik Millstone, Eric Brunner and Sue Mayer, who argued in a commentary in Nature that the substantial equivalence standard was pseudo-scientific and was the product of politics and business lobbying. They claimed it was created primarily to reassure consumers and to aid biotechnology companies in avoiding the time and cost of more rigorous safety testing. They suggested that all GM foods should have extensive biological, toxicological and immunological tests and that the concept of substantial equivalence should be abandoned. This commentary was criticized for providing a misleading presentation of history, for distorting existing data and applying bad logic Substantial equivalence does not measure risks, but instead identifies differences between existing products and new foods, which might pose dangers to health. If differences do exist, identifying these differences is a starting point for a full safety assessment, rather than an end point. It concluded that "The concept of substantial equivalence is an adequate tool in order to identify safety issues related to genetically modified products that have a traditional counterpart". In case of Non-Substantial Equivalence, if the GM plant or one of its components is not similar to its conventional varieties then the following unexpected differences could arise: (a) Pleiotropy: The transgene not only result in the expected new trait, but also results in another unexpected change in the plant. Like the transgene product can interact unexpectedly with other components in the plant. The pathway in which the transgene product has its function is (unexpectedly) cross linked with other pathways. Changed expression level of an enzyme may trigger other pathways or a down 
regulation response. (b) Insertion: The transgene has landed somewhere in a gene thereby disrupting this gene's function and resulting in changes in the plant's constituents. (c) Somaclonal Variation: In the in-vitro regeneration of the transgenic plants, due to chromosomal instability, changes have appeared in the plant resulting in changes in morphology, behavior, or macro- or micro constituents. But these unexpected effects are not yet understood totally and these nonsubstantial equivalence results in a need for further analysis. In certain countries, the regulatory authority for GM foods is the same authority that is responsible for administering food safety law(s). Like The United States looks at GMOs as being substantially equivalent to conventional crops and fall under Generally Recognized As Safe (GRAS) labeling and regulations. This recognizes that the safety assessment of GM foods is part of, and not separate from programs that address the broader context of ensuring the safety of the foods that the public consumes. In India, FSSAI (Food Safety and Standards Authority of India) as the statutory body for 'laying down science based standards for articles of food and regulating manufacturing, processing, distribution, sale and import of food so as to ensure safe and wholesome food for human consumption. FSSAI is the agency responsible for administering or determining the substantial equivalence of GM crop.

\section{Allergenicity}

Some environmental organizations such as the European Green Party and Greenpeace have suggested that GM food might trigger food allergies. Allergy of the results from allergen testing of current GM foods stated that "no biotech proteins in foods have been documented to cause allergic reactions". The developments of GM products which have been found to cause allergic reactions have been halted by the companies developing them before they were brought to market. In the early 1990s, Pioneer Hi-Bred attempted to improve the nutrition content of soybeans intended for animal feed by adding a gene from the Brazil nut. In 2005, a pest-resistant field pea developed by the Australian Commonwealth Scientific and Industrial Research Organization for use as a pasture crop was shown to cause an allergic reaction in mice. Work on this variety was immediately halted. Toxicologists note that "conventional food is not risk-free; allergies occur with many known and even new conventional foods. For example, the kiwi fruit was introduced in the U.S. and the European markets in the 1960s with no known human allergies; however, today there are people allergic to this fruit". Genetic modification can also be used to remove allergens from foods, potentially reducing the risk of food allergies. In ryegrass, pollen that is a major cause of hay fever but a fertile GM grass was produced that lacked the main pollen allergen, demonstrating that the production of hypoallergenic grass is also possible.

\section{Horizontal gene transfer}

In 2004 a study involving human volunteers was conducted to see if the transgene from GM soybean would transfer to the bacterium that naturally lives in the human gut. The transgene was only detected in three volunteers, part of seven who had previously had their large intestines removed for medical reasons. As this gene transfer did not increase after the consumption of GM soy, the researchers concluded that gene transfer did not occur during the experiment. In volunteers with complete digestive tracts, the transgene did not survive passage through intact gastrointestinal tract. The antibiotic genes used in genetic engineering are already found in many natural pathogens, commonly used during animal husbandry and not widely used prescribed. 
Fig.1 World acreage of GM crops. The area is being surpassed in developing countries from year 2010 onwards

\section{GLOBAL AREA OF BIOTECH CROPS Million Hectares (1996-2015)}

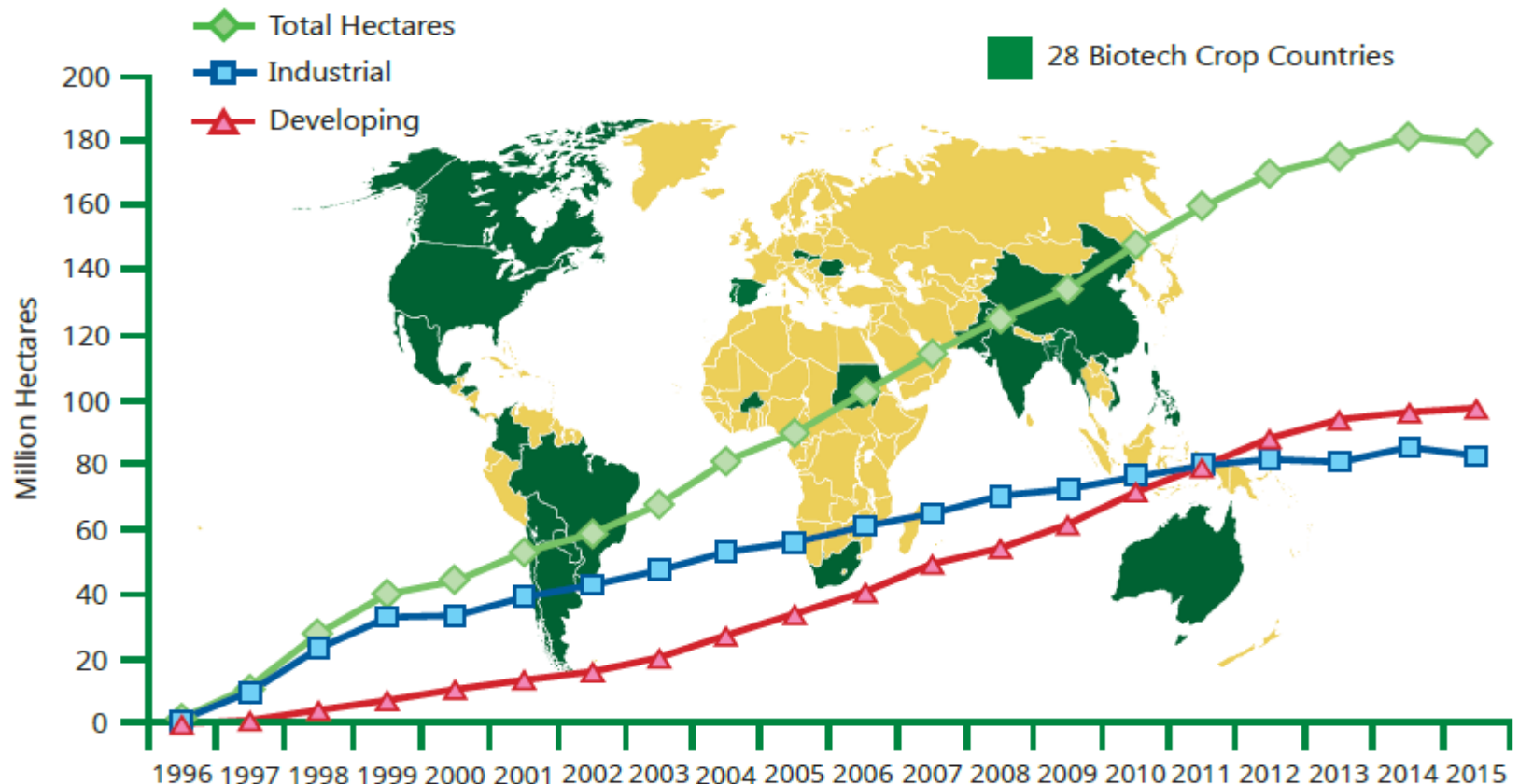

Fig.2 Countries growing GM crops

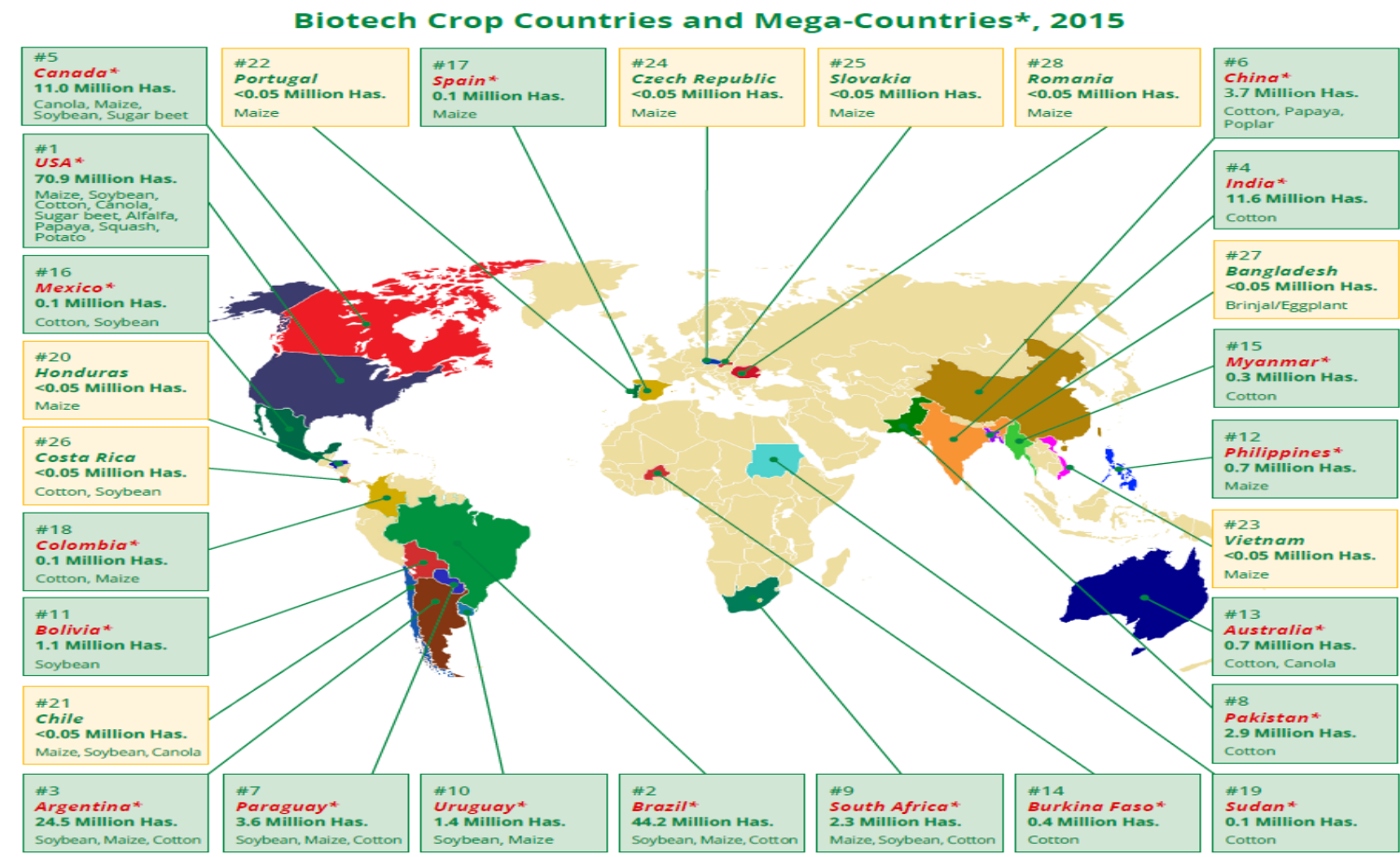


Fig.3 Adoption of Bt cotton in India

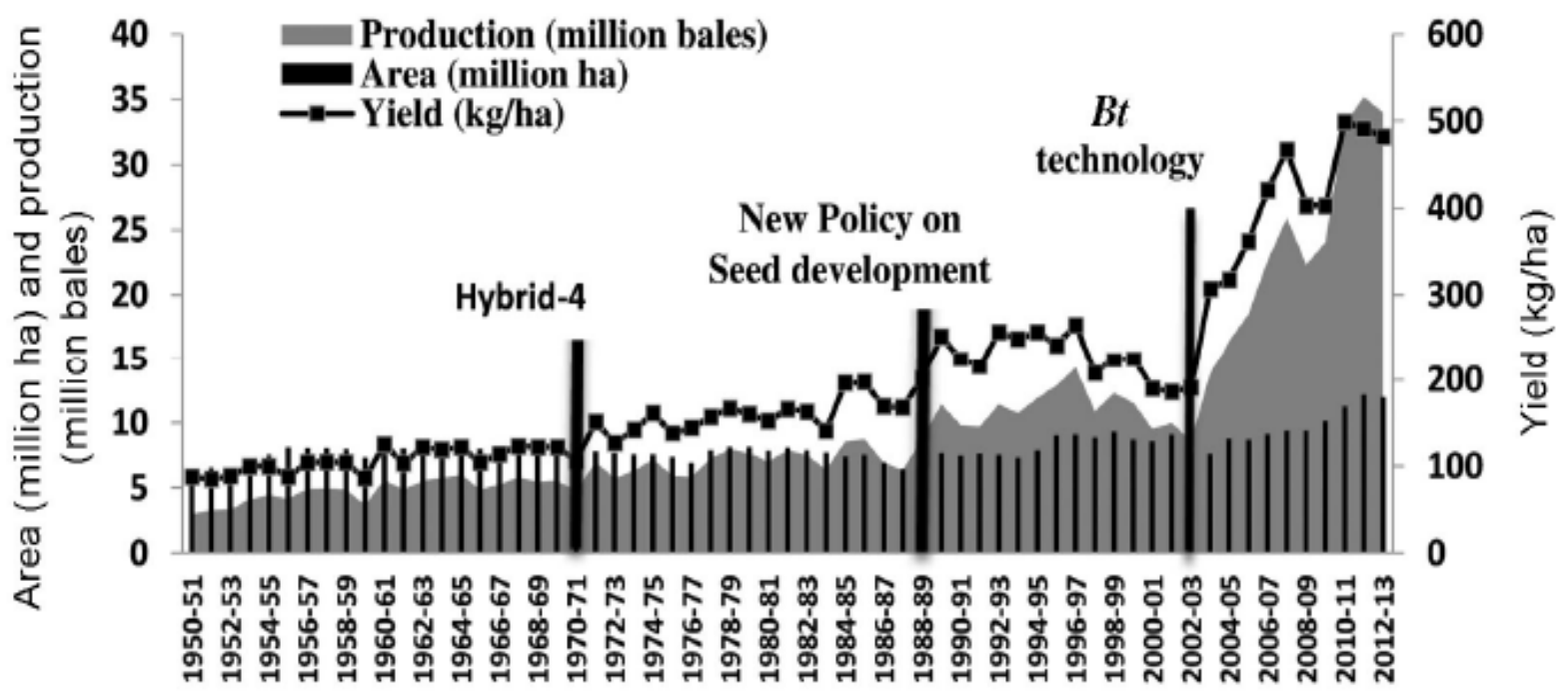

Year

Fig.4 Flow diagramme showing the system of how biosafety functionary works in India

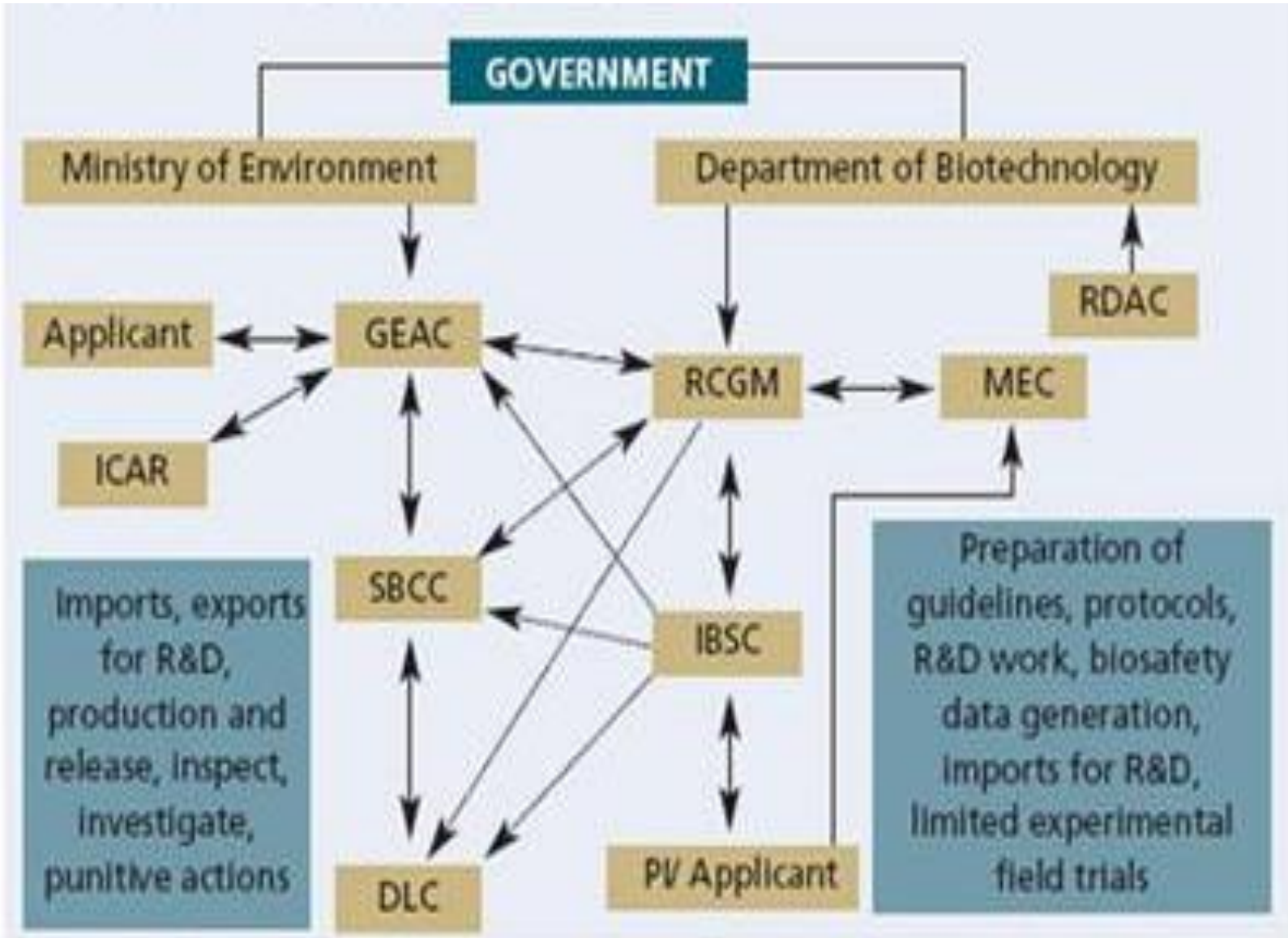


The risk of horizontal gene transfer between plants and animals is very low. The Monarch Butterfly Controversy: A paper published in Nature by Cornell researcher John E. Losey regarding the interaction between Monarch butterflies and the pollen released by GMO maize which expressed the Bt toxin. This paper reported that Monarch larvae which consumed pollen from $\mathrm{Bt}$ maize and dusted on milkweed leaves died. The period in which Monarch larvae occur and are feeding on milkweed leaves has a very little overlapping with the period in which Bt maize is actively shedding pollen, reducing the exposure time frame. Milkweed is not a preferred food supply of Monarch larvae and only a portion of the larvae is consuming this species. Other butterfly and moth species showed no evidence of elevated toxicity or mortality in real-world experiments. There are concerns that the Cry toxin encode by Cry gene genes from Bacillus thuringiensis could target predatory and other beneficial or harmless insects as well as the targeted pest insect. The proteins produced by $\mathrm{Bt}$ have been used as organic sprays for insect control in France since 1938 and the USA since 1958 with no ill effects on the environment reported. Gene flow from a genetically modified organism will pass to another organism just like an endogenous gene. There are concerns that the spread of genes from modified organisms to unmodified relatives could produce species of weeds resistant to herbicides or could disrupt the ecosystem. This is primarily a concern if the transgenic organism has a significant survival capacity and can increase in frequency and endures in natural populations. In November 2009, Monsanto scientists found the pink bollworm had become resistant to the first generation Bt cotton in parts of Gujarat, India. This generation expresses one Bt gene, CrylAc. This was the first instance of $\mathrm{Bt}$ resistance confirmed by Monsanto anywhere in the world. Bollworm resistance to first generation Bt cotton has also been identified in the Australia, China, Spain and the United States. The European Union, Australia, China, and other countries require GMO labeling, while others make GMO labeling voluntary or have plans to introduce labeling.

\section{Safety protocol in India for transgenic crops}

In India, the path of transgenic crops from the laboratory to the market involves five main stages: laboratory test, greenhouse test, contained field tests, large-scale field trials and approval by the bio-safety and other regulatory authorities for varietal tests and commercialization. In 1989 India established this regulatory system for the import, testing and commercialization of genetically test engineered material. It is based on the biosafety guidelines first developed and implemented in some of the leading Organizations for Economic Co-operation and Development (OECD) countries. They covered the health safety of humans and livestock, environmental safety (ecology and biodiversity) and economic impact. It comprised of the following three committees:

The Review Committee on Genetic Manipulation (RCGM) under the Ministry of Science and Technology (MoST).

The Genetic Engineering Approval Committee (GEAC) under the Ministry of Environment and Forestry (MoEF).

The Monitoring and Evaluation Committee (MEC) under DBT/MoST.

The regulations classify activities involving GMOs into four risk categories: Category I comprises routine recombinant DNA experiments conducted inside a laboratory. Category II consists of both laboratory and greenhouse experiments involving transgenes that combat biotic stresses through resistance 
to herbicides and pesticides. Categories III and IV comprise experiments and field trials where the effect of transgenic traits into the open environment could cause significant alterations in the ecosystem.

\section{Institutes/Organizations involved regulation of GM crops in India}

Recombinant DNA Advisory Committee (RDAC): This committee is constituted by DBT to monitor the developments in biotechnology at national and international levels. RDAC submits recommendations from time to time that are suitable for implementation for upholding the safety regulations in research and applications of GMOs and products thereof. This committee prepared the first Indian recombinant DNA biosafety guidelines in 1990, which were adopted by the Government for handling of GMOs and conducting research on them. Institutional Biosafety Committee (IBSC): It is composed of scientists engaged in rDNA work, biosafety or medical officer, nominee department of biotechnology. Its main function is to oversee rDNA research activities, to seek RCGM approval for category, to inform DLC, SBCC and GEAC about relevant experiment. This committee is constituted by organizations involved in recombinant DNA (r-DNA) research. It has the mandate to approve low-risk (Category I and II) experiments and to ensure adherence to r-DNA safety guidelines. IBSC recommends category III or above experiments to Review Committee on Genetic Manipulation (RCGM) for approval. It also acts as a nodal agency for interaction with various statutory bodies.

Review Committee on Genetic Manipulation (RCGM): It comes under the Department of Biotechnology (DBT) of the Ministry of Science and Technology (MoST). Its composition includes department of biotechnology, Indian Council of Agricultural Research, And Council of Scientific and Industrial Research. Its main function is to issue guidelines for GMO research, to authorized rDNA projects in high risk category, to authorized controlled field experiments, to permit import of GMOs for research. This committee is constituted by DBT to review all ongoing projects involving high-risk (Category III and above) and controlled field experiments. These small experimental field trials, also called Biosafety Research Level I (BRL I), are limited to a total area of 20 acres in multi-locations in one crop season. In one location where the experiment is conducted with transgenic plants, the land used should not be more than 1 acre. RCGM approval is granted for one season and applicant must provide entire details of the experimentation to the committee. Monitoring of field trials is carried out by Monitoring cum Evaluation Committee of RCGM. RCGM can lay down procedures restricting or prohibiting production, sale, importation and use of GMOs. It also issues clearances for import/export of etiologic agents and vectors, transgenic germplasm including transformed calli, seed and plant parts for research use only.

Genetic Engineering Approval Committee (GEAC): It comes under the Ministry of Environment and Forestry (MoEF). Its composition includes Chairman, additional secretary Ministry of Environment and Forests, Co-chair Department of Biotechnology and Atomic Energy, Indian Council of Medical Research, Council of Scientific and Industrial Research, Directorate of Plant Protection, Central Pollution Control Board and other in individual capacity. Its main function is to authorize commercial use (including imports) of GMO or their products. To authorized large-scale production and release of GMOs and their products into the 
environment to mandate restrictions and prohibitions on production, sale, and import of GMOs, if necessary. This committee functions as a body in the Ministry of Environment and Forests and is responsible for environmental approval of activities involving large-scale use of GMOs in research, industrial production and applications. Large-scale experiments conducted in an area of 2.5 acres per location also known as Biosafety Research Level II (BRL II) beyond the limits specified within the authority of RCGM are authorized by GEAC. The GEAC can authorize approval and prohibition of any GMO for import, export, transport, manufacture, processing use or sale.

State Biotechnology Coordination Committee (SBCC): Its composition includes Chief Secretary (state government), secretaries, (department of environment) health, agriculture, commerce, forest, public work, public health, State Pollution Control Board, State Microbiologist and Pathologists, other experts in individual capacity. Its main Function is to periodically review safety and control measures in institutions handling GMOs, to inspect and take punitive action in case of violations through the state pollution control board or the directorate of health, to act as nodal agency at the state level to assess damage, if any, from release of GMOs and to take of site control measures. The Committee is also nominates state government representatives for field inspection of GM crops.

District Level Committee (DLC): Its Composition includes District Collector, factory inspector, pollution control board, representative chief medical officer, district agricultural officers, public health department representative, district microbiologist/pathologist, Municipal Corporation, commissioner, other experts in individual capacity. Its main Function is to monitor safety regulation in installation, to investigate compliance with rDNA guidelines and report violations to SBCC or GEAC, to act as nodal agency at district level, to assess damage, if any from release of GMOs and to take on site control measures. The District Collector heads the committee who can induct representative from state agencies to enable smooth functioning and inspection.

Monitoring and Evaluation Committee (MEC): This committee comes under DBT/MoST. DBT provides the secretariat for RCGM and MEC. Its Composition includes Chairman, jointly elected by secretary (Department of Biotechnology) and secretary (Department of Agricultural Research and Education), plant breeders (nominated by RCGM or ICAR) and the National Bureau of Plant Genetic Resources (NBPGR) nominee, a MoEF nominee and the member secretary of the RCGM. Its main Function is to undertake field visits at experiment sites, to suggest remedial measures, to adjust original trial design, to assist RCGM in collecting and analyzing field data to collect comparative agronomic advantages of transgenic plants. This system has some deficiencies. Current protocols focus largely on screening for toxic effects of chemicals, rather than biological impacts. A striking feature of the composition of RCGM, GEAC and MEC is the absence of the representatives of other crucial stakeholders e.g. civil society organizations (CSOs, including NGOs), private sector companies and institutions, and the central government funded Indian Council for Social Science Research (ICSSR). While the regulations say that the RCGM, the GEAC, the SBCCs and the DLCs may co-opt other members/experts as necessary, they do not include representatives of CSOs/NGOs and the private sector. In practice, however, these non-governmental stakeholders have been excluded. 
Coordination between the functionary infrastructures for the development of GM crops

For commercialization of transgenic crops, every applicant has to take approval first from Institutional Bio-safety Committee (IBSC). It is composed of scientists of rDNA, medical officers and nominee of department of biotechnology. Its main function is to oversee rDNA research activity. It seeks RCGM approval for category III and informs the District level Committee (DLC), State Biotechnology Coordination Committee (SBCC) \& Genetic Engineering Appraisal Committee (GEAC) about relevant experiments. DLC composed of District collector, factory inspectors, pollution control board and other experts in individual capacity. It monitors safety regulation in installation and report violations to SBCC or GEAC.

SBCC consists of chief secretary, Department of Environment, State Pollution Control Board, microbiologists, pathologist and other experts in individual capacity. Its main function is to periodically review the safety and control measures in institution handling GMOs. It inspects and takes punitive action in case of violations through the State Pollution Control Board. SBCC acts as a nodal agency to assess damage and take of site control measures also. At second stage of commercialization of transgenic crops, RCGM comes into picture. It works under the Department of Biotechnology (DBT) of the Ministry of Science and Technology (MoST). The main function of RCGM is to issue guidelines for GMO research and authorize rDNA project in high risk category III. It also authorizes controlled field experiments and permits the import of GMO for research. At this stage RCGM's mandate is to assess and decide on the applications submitted by institutions and companies for conducting $\mathrm{R} \& \mathrm{D}$ work, greenhouse tests and contained field tests on plots of less than one acre in size (0.4 hectare). RCGM also cooperate with Monitoring and Evaluation committee (MEC). It does monitoring work and its reports are expected to cover all the main aspects of bio-safety, i.e. the impact of the GM-crop on the environment (ecology and biodiversity), the agronomy (crop production science and farm-level economy), the health of humans and livestock and the livelihoods of the farming community. It collects information on comparative agronomic advantages of transgenic plants and assists RCGM in collecting and analyzing field data at experiment side. After these two stages, towards general release and commercialization of transgenic crops, large scale and multi-location field trials are mandatory under the biosafety regulation. At this stage GEAC has the sole responsibility and power to authorize large-scale and multilocation field trials, and assess the output of the trials. On the basis of that assessment GEAC decide to approve, reject or put on hold the applicant's request for general release of the GM-crop for commercial planting. GEAC may request ICAR to check and validate the 'output' of field trials submitted by the applicant, if necessary by conducting its own field trials. Indian Council for Agricultural Research (ICAR) is an autonomous body under the Department of Agricultural Research and Education of the Ministry of Agriculture. After investigation of the applicant, State government provides permission for commercialization of crops.

\section{Some recent event for transgenics crops}

Innate generation $1 \& 2$ Potato developed by Simplot, was first commercialized on 160 ha in US (2015)

US canola, first non-transgenic genome edited crop developed by Cibus was commercialized with grown 4000 ha in 2015 
Artic apple with less bruissing and less browning when sliced were approved for planting in USA (6 ha) and Canada

Alfalfa (KK197) world first forage transgenic crop commercialized in 2016

DroughtGard tolerant maize with high farmer acceptance in US (2013 - 50000 ha, 2014 275000 ha, $2015-810000$ ha)

Vietnam (Staked GM maize) was first time commercialized in 2015

Bt eggplant in Bangladesh planted in 2014 (12 ha) and 2015 (25 ha)

CRISPR genome editing technology was selected by Science magazine as breakthrough technology of 2015

Genetic Engineering Appraisal Committee (GEAC), on $11^{\text {th }}$ May 2017 cleared the genetically modified (GM) Mustard for commercial cultivation and recommended its approval to the Ministry of Environment and Forests \& Climate Change

GM Mustard is safe for human consumption and environment

Dhara Mustard Hybrid-11 (DMH-11) will become the first GM food crop to be cultivated in Indian farms.

\section{References}

Bandopadhyay R, Sinha P and Chaudhary B (2012) Is Bt. brinjal ready for future crop?-A critical study. Indian $J$ Biotech.11:238-40.

Domingo J L (2007) Toxicity studies of genetically modified plants: a review of the published literature. Crit Rev Food Sci Nutr. 47: 721-33.
Domingo J L and Bordonaba J G (2011) A literature review on the safety assessment of genetically modified plants. Env International. 37: 734-42.

Flachowsky G, Chesson A and Aulrich K (2005) Animal nutrition with feeds from genetically modified plants. Arch Anim Nutr 59: 1-40.

Jiang X. and Xiao G. (2010) Detection of unintended effects in genetically modified herbicide-tolerant (GMHT) rice in comparison with non-target phenotypic characteristics. African $J$ Agri Res. 5:1082-88.

Kappeli O (1998) How safe is safe enough in plant genetic engineering? Trends in $\mathrm{Pl}$ Sci. 3: 276-81.

Kathage J and Qaim M (2012) Economic impacts and impact dynamics of $\mathrm{Bt}$ (Bacillus thuringiensis) cotton in India. Proc. Natl. Acad. Sci. U.S.A. 109:11652-6.

Keese P (2008) Risks from GMOs due to Horizontal Gene Transfer. Env Biosafety Res. 7: 123-149.

Lehrer S B and Bannon G A (2005) Risks of allergic reactions to biotech proteins in foods: perception and reality. Allergy. 60: 559-64.

Lucht J M (2015) Public Acceptance of Plant Biotechnology and GM Crops.Viruses.7: 4254-81

Nordlee J A, Taylor S L, Townsend J A, Thomas L A and Bush R K (1996) Identification of a Brazil-nut allergen in transgenic soybeans. $N$ Engl $\mathrm{J}$ Med. 334: 688-92.

Randhawa G J and Chhabra R (2009) Import and Commercialization of Transgenic Crops: An Indian Perspective. Asian Biotech and Dev Review. 11:115-30

Romeis J R, Bartsch D, Bigler F, Candolfi M P, Gielkens M M C, Hartley S E, Hellmich R L and Huesing J E (2008) Assessment of risk of insect-resistant 
transgenic crops to nontarget arthropods. Nature Biotech. 26: 203-08.

Wang F, Dang C, Chang X, Tian J, Lu Z, Chen $Y$ and Ye G (2017) Variation among conventional cultivars could be used as a criterion for environmental safety assessment of $B t$ rice on nontarget arthropods. Scientific Reports: $1-9$

Zhang C, Wohlhueter R and Zhang H (2016) Genetically modified foods: A critical review of their promise and problems. Food Sci and Human Wellness. 5:11623

\section{How to cite this article:}

Manoj Kumar, S.P. Singh, Mankesh Kumar, Anand Kumar, Satyendra Kumar and Priti Kumari. 2018. Biosafety Issues in Commercialization and Development of Transgenic Crops. Int.J.Curr.Microbiol.App.Sci. 7(04): 2161-2174. doi: https://doi.org/10.20546/ijcmas.2018.704.246 